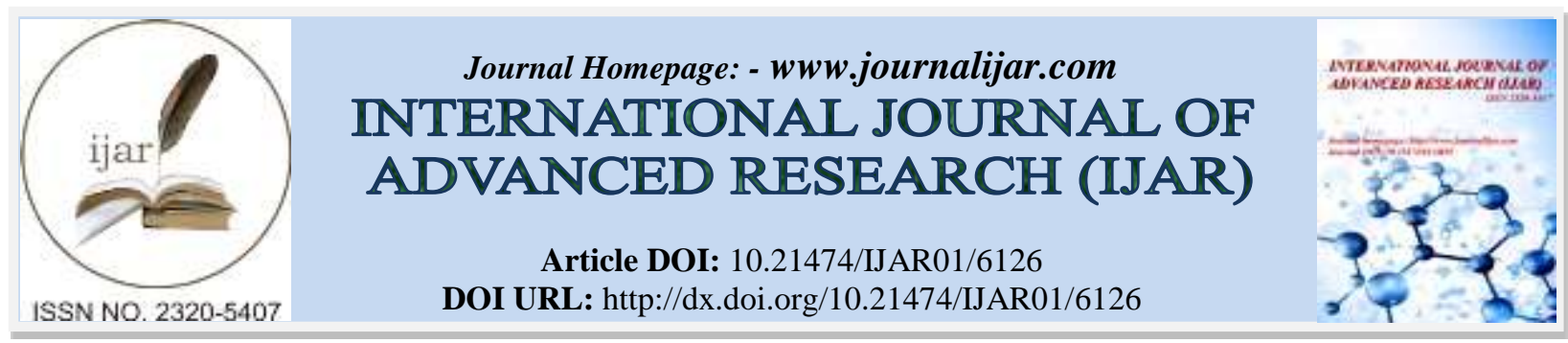

RESEARCH ARTICLE

\title{
CLINICAL AND LABORATORY EVALUATION OF ADRENOMEDULLIN AS A BIOMARKER IN MODERATE CHRONIC PERIODONTITIS.
}

Shahawi M. Salim ${ }^{1}$, Jilan M. Youssef ${ }^{2}$, Shereen Salah $^{3}$ and Mohamed M. Anees ${ }^{4}$.

1. B.D.S. Faculty of Dentistry Sirte University, Libya.

2. Professor of Oral Medicine and Periodontology, Faculty of Dentistry, Mansoura University.

3. Professor of Clinical Pathology, Faculty of Medicine, Mansoura University.

4. Ass. Professor of Oral Medicine and Periodontology, Faculty of Dentistry, Mansoura University.

\section{Manuscript Info}

(..........................

Manuscript History

Received: 21 October 2017

Final Accepted: 23 November 2017

Published: December 2017

Keywords:-

Adrenomedullin, Interleukin-1 $\beta$, biomarkers, chronic periodontitis.

\section{Abstract}

Objective: The aim of this study was to determine the effect of non surgical periodontal treatment on GCF level of adrenomedullin and interleukin 1 Beta in patients with moderate chronic periodontitis.

Subjects and Methods: A total of thirty subjects was included in this study; 15 subjects with moderate chronic periodontitis (group I) and 15 systemically healthy subjects with clinically healthy gingiva as a control group (group II). Periodontal parameters, including Plaque index (PI), Gingival index (GI), bleeding on probing (BOP), Periodontal probing depth (PPD) and Clinical attachment level (CAL), were recorded in all the sites from both groups. The first GCF samples were collected from both groups (study and control) at the start of study. Nonsurgical periodontal therapy was done to group I. The same periodontal parameters were recorded again and the second GCF samples were collected again after 4 weeks after phase I therapy from group I. Levels of IL-1 $\beta$ and adrenomedullin in GCF were quantified using ELISA.

Results: At baseline the level of IL-1 $\beta$ and ADM in gingival crevicular fluid was significantly higher in chronic periodontitis patients than in healthy subjects. The results of the present study, showed a significant reduction in all clinical parameters (GI, PI, PPD, BOP and CAL) after phase I periodontal therapy in chronic periodontitis group. Level of IL$1 \beta$ and $\mathrm{ADM}$ in gingival crevicular fluid were significantly decreased after a phase I periodontal therapy in moderate chronic periodontitis group when compared to their levels at baseline.

Conclusions: Scaling and root planing (SRP) is the mainstay of treatment of periodontal diseases as SRP was effective in improving clinical parameters in patients with chronic periodontitis. ADM could be used as a potential diagnostic marker for periodontal disease in gingival crevicular fluid.

Copy Right, IJAR, 2017,. All rights reserved. 


\section{Introduction:-}

Periodontitis is a group of inflammatory diseases that affect the connective tissue attachment and supporting bone around the teeth whose initiation and progression depends primarily on the presence of virulent microorganisms capable of causing disease. ${ }^{(1)}$ However the interactions between the host defense mechanism and microbial challenge are important factors for the susceptibility of the host to periodontitis, so periodontitis is considered to be a multifactorial disease. ${ }^{(2)}$

There are many cytokines, such as IL- 1 and TNF- $\alpha$, reported to have an important role in the inflammatory process. IL-1 is one of the most important of these cytokines that stimulates bone resorption and inhibits bone formation. This mediator also stimulates the prostaglandin synthesis and protease production. ${ }^{(3)}$

Interleukin-1 $\beta$ (IL-1 $\beta$ ) is an important mediator of inflammatory response and is involved in cell proliferation, differentiation, and apoptosis, and in the pathophysiology of periodontitis. Several studies reported a correlation between the inflammatory status of periodontal disease and IL-1 $\beta$ levels in gingival tissues and gingival crevicular fluid (GCF). ${ }^{(4)}$

Antimicrobial peptides including defensins, cathelicidin, and human neutrophil peptide (HNPs) participate in the innate host response of organisms, and they are important contributors for maintaining the balance between health and disease. ${ }^{(2),(5)}$ The role of antimicrobial peptides activity is constantly exposure to a variety of microbial pathogens. ${ }^{(2)}$

Adrenomedullin (ADM), is one of the important antimicrobial peptides having a role in the innate host defence. ADM is constitutively expressed and secreted by oral epithelial cells. Epithelial cells secrete ADM when they are exposed to various bacterial species and inflammatory cytokines. ${ }^{(6)}$ Adrenomedullin shares its mechanism of antimicrobial activity with other cationic antimicrobial peptides. Although exact mechanism is still not elucidated, ADM is thought to promote intramembranous pore formation in bacterial cell membrane, resulting in stoppage of bacterial critical intracellular processes and finally bacterial cell death. ${ }^{(7)}$

\section{Patients and methods:-}

A total of thirty subjects were enrolled in this study. Patients were chosen from those attending periodontal treatment at the Department of Oral Medicine and Periodontology, Faculty of Dentistry, Mansoura University. Fifteen of them were diagnosed as moderate chronic periodontitis patients determined by clinical and radiographic examination according to American Academy of Periodontology to classification of periodontal diseases (1999). Fifteen healthy subjects were selected as control group.

\section{Subjects population :-}

The selected patients were divided into two groups as follow

Group I (study group): 15 patients suffering from moderate chronic periodontitis.

Group II (control group):15 subjects were chosen as healthy subjects with no signs or symptoms of gingival or periodontal disease.

The selected patients were free from any autoimmune or systemic diseases, and receiving no medications like antibiotic and anti-inflammatory drugs which may affect microbial flora, immune system, or the inflammatory response for at least the last 3 months. Furthering, none of them had periodontal treatment in the last six months.

\section{Methods:-}

At the first appointment periodontal parameters as well as GCF samples were taken for all participants. Then, patients were treated once a week by scaling \& root planning using ultrasonic scaler \& hand instruments. Patients were instructed to establish good oral hygiene in the form of daily teeth brushing and dental flossing. After 4 weeks of treatment, periodontal parameters and the second GCF samples were taken.

\section{Clinical Periodontal parameters:-}

Gingival index (GI), Plaque index (PI), Bleeding on Probing Index (BOP), Probing Pocket Depth (PPD) and Clinical Attachment Loss (CAL) were measured at the beginning of the study to both groups \& after four weeks of treatment in study group. 


\section{Collection of gingival crevicular fluid (GCF) sample:-}

In both groups, GCF samples were collected at the initial visit and in group I after four weeks of treatment. Clinically detected supra gingival plaque was removed carefully without touching the marginal gingiva to minimize contamination of the paper strips by the plaque. The teeth were then gently washed with water, and the sites under study were isolated with cotton rolls to prevent contamination with saliva and gently dried with an air syringe. One sterile paper point was used for each collection site. GCF samples were collected from only 2 sites in each of the diseased participants and the healthy controls. Paper point were carefully inserted into the gingival crevice until mild resistance was felt and left there for 30 seconds. Following collection of GCF the paper point placed in eppendroffs tube contain phosphate buffer saline and stored at $-80^{\circ} \mathrm{C}$ for later processing. Paper points for each participant were pooled, and the GCF was extracted and assayed for the levels of interleukin-1 $\beta$ (IL-1 $\beta$ ) and Adrenomedullin $(\mathrm{ADM}){ }^{(8)}$

\section{GCF IL1 $\beta$ and ADM analysis:-}

The levels of IL1 $\beta$ and ADM were determined with the use of commercially available enzyme-linked immune sorbent assay (ELISA) kit following the manufacturer instructions.

\section{Result:-}

Group I (6 males and 9 females). Group II (2 males and 13 females)

Table (1) illustrates the difference between study and control groups as regard clinical and laboratory parameters before treatment. Plaque index showed a high statistically significant difference $(p<0.001)$ between study group and control group at base line with higher mean \pm SD plaque index in study group $(2.37 \pm 0.26)$ than control group $(0.531 \pm 0.09)$. Gingival index showed a high statistically significant difference between studied groups $(p<0.001)$ with higher mean gingival index in study group than control group $(2.14 \pm 0.1 \& 0.27 \pm 0.08$ respectively). Bleeding on probing index illustrated a high statistically significant difference between studied groups $(p<0.001)$ with higher mean in study group $(0.92 \pm 0.08)$ than control group $(0.19 \pm 0.07)$. Probing pocket depth illustrated a high statistically significant difference between studied groups $(p<0.001)$ with higher mean in probing pocket depth in study group (3.07 \pm 0.4$)$ than control group $(0.92 \pm 0.06)$. Interleukin- $1 \beta$ level $(\mathrm{pg} / \mathrm{ml})$ showed statistically significant higher mean value in study group $(33.32 \pm 3.96)$ than control group $(21.32 \pm 2.23)$ at $p<0.001$. Adrenomedullin level $(\mathrm{pg} / \mathrm{ml})$ showed statistically significant higher mean value in study group (17.73 \pm 1.9$)$ than control group $(11.0 \pm 1.6)$ at $p<$ 0.001 .

Table (1):- Comparison between study and control groups in clinical and laboratory parameters before treatment.

\begin{tabular}{|c|c|c|c|}
\hline PI & $2.37 \pm 0.26$ & $0.531 \pm 0.09$ & $\mathrm{t}=26.3 \mathrm{p}<0.001^{* *}$ \\
\hline GI & $2.14 \pm 0.1$ & $0.27 \pm 0.08$ & $\mathrm{t}=55.86 \mathrm{p}<0.001^{* *}$ \\
\hline BOP & $0.92 \pm 0.08$ & $0.19 \pm 0.07$ & $\mathrm{t}=27.49 \mathrm{p}<0.001^{* *}$ \\
\hline PPD & $3.07 \pm 0.4$ & $0.92 \pm 0.06$ & $\mathrm{t}=20.1 \mathrm{p}<0.001^{* *}$ \\
\hline IL-1 $\beta$ level $(\mathrm{pg} / \mathrm{ml})$ & $33.32 \pm 3.96$ & $21.32 \pm 2.23$ & $\mathrm{t}=10.2 \mathrm{p}<0.001^{* *}$ \\
\hline ADM level $(\mathrm{pg} / \mathrm{ml})$ & $17.73 \pm 1.9$ & $11.0 \pm 1.6$ & $\mathrm{t}=10.57 \mathrm{p}<0.001^{* *}$ \\
\hline
\end{tabular}

Table (2) illustrate the change in clinical and laboratory indices after treatment in study groups. The mean and standard deviation of plaque index at baseline was $2.37 \pm 0.26$ and after four weeks of treatment became $0.66 \pm 0.14$. There was a highly statistically significant improvement between plaque index values at baseline and four weeks after treatment $(P<0.001)$. The mean and standard deviation of gingival index at baseline was $2.14 \pm 0.1$ and after four weeks of treatment became $0.59 \pm 0.12$. There was a statistically highly significant difference between gingival index values at baseline and four weeks after treatment $(P<0.001)$. The mean and standard deviation value of bleeding on probing index at baseline was $0.92 \pm 0.08$ and after four weeks of treatment became $0.29 \pm 0.07$. There was a highly significant difference between bleeding on probing index values at baseline and four weeks after treatment $(P<0.001)$. The mean and standard deviation of probing pocket depth at baseline was $3.07 \pm 0.4$ and after four weeks of treatment was $1.03 \pm 0.16$. There was a statistically highly significant difference between probing pocket depth values at baseline and 4 weeks after treatment $(P<0.001)$. Regarding the clinical attachment level at baseline, the mean and standard deviation was $3.11 \pm 0.38$ versus its values after four weeks of treatment $1.054 \pm 0.16$. There was a highly significant difference between clinical attachment level values at baseline and four weeks after treatment $(P<0.001)$. The mean and standard deviation of IL-1 $\beta$ at baseline was $33.32 \pm 3.96$ and after four weeks of treatment became $23.09 \pm 3.8$. There was a high statistically significant decrease in the level of IL-1 $\beta$ in GCF 
between baseline and four weeks after treatment $(p<0.001$. The mean and standard deviation of ADM at baseline was $17.73 \pm 1.9$ and after 4 weeks of treatment became $11.93 \pm 1.99$. There was a high statistically significant difference in the level of ADM in GCF between baseline and 4 weeks after treatment $(\mathrm{p}<0.001)$.

Table (2):- Comparison of clinical and laboratory indices before and after treatment in study group.

\begin{tabular}{|c|c|c|c|}
\hline $\begin{array}{c}\text { Clinical \&laboratory } \\
\text { indices }\end{array}$ & Before & After & Test of significance \\
\cline { 2 - 4 } & Mean \pm SD & Mean \pm SD & \\
\hline PI & $2.37 \pm 0.26$ & $0.66 \pm 0.14$ & $\begin{array}{c}\mathrm{t}=25.6 \\
\mathrm{p}<0.001^{* *}\end{array}$ \\
\hline GI & $2.14 \pm 0.1$ & $0.59 \pm 0.12$ & $\begin{array}{c}\mathrm{t}=55.2 \\
\mathrm{p}<0.001^{* *}\end{array}$ \\
\hline BOP & $0.92 \pm 0.08$ & $0.29 \pm 0.07$ & $\begin{array}{c}\mathrm{t}=29.6 \\
\mathrm{p}<0.001^{* *}\end{array}$ \\
\hline PPD & $3.07 \pm 0.4$ & $1.03 \pm 0.16$ & $\begin{array}{c}\mathrm{t}=21.3 \\
\mathrm{p}<0.001^{* *}\end{array}$ \\
\hline CAL & $3.11 \pm 0.38$ & $1.054 \pm 0.16$ & $\begin{array}{c}\mathrm{t}=22.5 \\
\mathrm{p}<0.001^{* *}\end{array}$ \\
\hline IL-1 $\beta$ level $(\mathrm{pg} / \mathrm{ml})$ & $33.32 \pm 3.96$ & $23.09 \pm 3.8$ & $\mathrm{t}=31.4$ \\
& $17.73 \pm 1.9$ & $11.93 \pm 1.99$ & $\mathrm{p}<0.001^{* *}$ \\
\hline ADM level $(\mathrm{pg} / \mathrm{ml})$ & & & $\mathrm{p}<49.5$ \\
& & & \\
\hline
\end{tabular}

In the correlation between Interleukin-1 $\beta$ level \& clinical indices in study group before and after treatment, there was no statistically significant correlation between Interleukin-1 $\beta$ \& clinical indices $(p>0.05)$. The correlation between Adrenomedullin level \& clinical indices in study group before and after treatment there found no statistically significant correlation between Adrenomedullin level \& clinical indices $(p>0.05)$. In the Correlation between laboratory \& clinical indices in control group, there was no significant correlation between either ADM or IL-1 $\beta$ with tested clinical parameters either than PPD only which showed moderate positive correlation with ADM $(r=0.569, p=0.027)$, while IL-1 $\beta$ showed significant moderate negative correlation $(r=-0.544, p=0.036)$ with plaque index .

\section{Discussion:-}

The fundamental event in the transition from gingivitis to periodontitis is the loss of soft tissue attachment of the tooth and subsequent loss of alveolar bone. Periodontitis is an inflammatory disease that leads to local elevation in levels of pro-inflammatory cytokine which plays a vital role in the process of inflammation associated with the destruction of the periodontium. ${ }^{(9)}$

The interaction of micro- organisms with the host immune system determines the course and severity of the resulting disease. It is generally accepted that much of the periodontal tissue destruction observed in periodontitis is host- mediated through release of proinflammatory cytokines by local tissues and immune cells in response to the bacterial flora and its products/metabolites, especially lipopolysaccharides. Antimicrobial proteins and peptides constitute a diverse class of host-defense molecules that act early to combat invasion and infection with bacteria and other microorganisms. ${ }^{(10)}$ Antimicrobial peptides (e.g defensins, cathelicidin and adrenomedullin) are an important part of the host innate immune response in gingival tissues. ${ }^{(1)}$ They are important contributors for maintaining the balance between the healthy and diseased conditions of the oral cavity. ${ }^{(2)}$

Gingival crevicular fluid as well as saliva represent a powerful vehicle, which contains various cellular and biochemical arrays for observation of tissue and cell products and permits a degree of non-invasive accessibility to the periodontium. ${ }^{(12)}$ Thus, the majority of new diagnostic tests for periodontal disease utilize these vehicles, ${ }^{(13)}$ and evaluation of the different tissue and cell markers in gingival crevicular fluid as well as saliva is regarded as a useful manner to determine a person's risk for periodontal disease. ${ }^{(14)}$

As the adrenomedullin concentrations in gingival crevicular fluid is about 30 -fold compared to saliva ${ }^{(15)}$ so in the present study gingival crevicular fluid was selected to assess adrenomedullin level in chronic periodontitis patients (moderate type). Gingival crevicular fluid samples were obtained from each subject by using absorbent filter paper 
point. The paper points were inserted into crevices or pockets until minimum resistance was felt for only 30 seconds. ${ }^{(16)}$ Careful isolation and plaque removal was performed prior to gingival crevicular fluid collection to prevent saliva or plaque contamination, and any filter paper contaminated with saliva, plaque or blood was discarded to avoid false results in the gingival crevicular fluid analysis procedure. ${ }^{(17)}$

Furthering, the present study was designed to evaluate if gingival crevicular fluid adrenomedullin could be considered as potential marker of periodontal inflammation and / or destruction in cases of moderate chronic periodontitis.

The evaluation of clinical parameters (GI, PI, BOP, PPD and CAL) revealed significant differences, between moderate chronic periodontitis patients at baseline and healthy subjects. These results were in accordance with Ghodpage ${ }^{(18)}$; Lamster and Ahlo ${ }^{(19)}$. They revealed statistically significant differences between chronic periodontitis patients at baseline and healthy subjects regarding the same clinical parameters.

The clinical parameters (GI, PI\& BOP) in moderate chronic periodontitis patients decreased significantly after phase I periodontal therapy versus their level at the baseline. These results were in agreement with $\mathbf{A b d u l ~ A z i z}$ et al where they found significant reduction in PI, GI, and POB, after phase I periodontal therapy. ${ }^{(20)}$

The significant intragroup differences in the form of the reported improvement of the measured clinical parameters after phase I therapy reinforce the importance of SRP as a basic therapeutic modality for chronic periodontitis. These results clarify the role played by scaling and root planning that eliminate the favorable environment for colonization of periodontopathogen resulting in reduction of the inflammatory response induced by the bacterial load and cessation of periodontal disease progression, manifested as reduction of probing pocket depth and a relative gain of clinical attachment. ${ }^{(21)}$

Regarding interleukin- $1 \beta$ concentration in gingival crevicular fluid, the results of the present study have shown that, there was a highly significant difference in the concentration of gingival crevicular IL-1 $\beta$ between the chronic periodontitis patients and control group at baseline. These findings were consistent with the results of many studies. They demonstrated that the concentration of interleukin-1 $\beta$ in gingival crevicular fluid was higher in patients with periodontitis than in individuals with clinically healthy sites of periodontium. Furthermore, in the present study there was a significant reduction in the level of intrleukin-1 $\beta$ in gingival crevicular fluid between the baseline and after four weeks of periodontal treatment. In agreement with the current data, other studies demonstrated a decrease in gingival crevicular fluid levels of interleukin-1 $\beta$ after phase I therapy. ${ }^{(22-24)}$

The noticed difference in IL-1 $\beta$ level among our studied groups (study and control) could be explained as IL-1 $\beta$ represent a kind of proinflammatory cytokine, which has a central role in regulating the immune system and is responsible for a variety of immune responses. As the IL-1 $\beta$ can influence a large number of cells, such as fibroblasts, chondroblasts, bone cells, neutrophils and lymphocytes, the periodontal destruction and periodontal regeneration can be partially related to this cytokine. ${ }^{(25)}$

Regarding the present study, adrenomedullin level in gingival crevicular fluid of moderate chronic periodontitis was compared with control group, and it was found that the total adrenomedullin levels in gingival crevicular fluid was significantly higher in moderate chronic periodontitis group at baseline. Lundy et al ${ }^{(6)}$ supported our data. They showed that, the total amount of gingival crevicular fluid adrenomedullin in periodontitis sites was higher than that of healthy sites. Similarly, our data was supported by Oya et al. ${ }^{(26)}$ They demonstrated that patients with periodontitis had a higher total amount of GCF adrenomedullin compared to healthy controls. Also, they added the total amount of gingival crevicular fluid adrenomedullin was significantly higher in periodontitis groups than that of the gingivitis group, and although not significant, there was a higher total amount of gingival crevicular fluid adrenomedullin in the gingivitis group compared to that of the healthy group. Other studies have reported higher adrenomedullin level in gingival crevicular fluid of chronic periodontitis patients as compared to periodontal health. ${ }^{(27-30)}$

The higher gingival crevicular fluid adrenomedullin levels in patient group could be due to the fact that it is constitutively expressed and secreted by oral epithelial cells and its expression increased in response to live oral bacteria, as lipopolysaccharide (LPS) is a potent stimulator of adrenomedullin secretion. ${ }^{(31)}$ Furthermore the increase of gingival crevicular fluid adrenomedullin levels was more prominent in patients with periodontitis 
because of the presence of more severe inflammation and periodontal destruction and an increase of bacteriastimulated adrenomedullin production by epithelial cells to protect the host from the bacterial invasion. ${ }^{(6,32-34)}$ Moreover, adrenomedullin production is controlled by various humoral factors and physical factors and inflammatory cytokines such as tumor necrosis factor TNF- $\alpha$, TNF- $\beta$, interleukin IL- $1 \alpha$ and IL- $1 \beta .{ }^{(35)}$

In the study group, regarding the level of adrenomedullin in gingival crevicular fluid, a significant reduction was found after phase I therapy in comparison to its level at baseline. To the best of our knowledge, no other studies in the literature evaluated the effect of phase I periodontal therapy on the level of adrenomedullinin in crevicular fluid. Thus, the present study was designed to evaluate the effect of phase I therapy on adrenomedullin level and searching for an answer of this question that may serve partly in more understanding of the exact role played by adrenomedullin in the pathogenesis of periodontal diseases. Since, this was the first study concerning this assessment of effect of scaling and root planing on crevicular level of adrenomedullin. So, we cannot know how many studies will be in agreement or disagreement with our results.

\section{Conclusions:-}

Scaling and root planing (SRP) is the mainstay of treatment of periodontal diseases as SRP was effective in improving clinical parameters in patients with moderate chronic periodontitis. ADM in gingival crevicular fluid could be used as a potential diagnostic marker for chronic periodontitis.

\section{References:-}

1. Socransky SS, Haffajee AD. The bacterial etiology of destructive periodontal disease: current concepts. Journal of Periodontology. 1992;63(4s):322-31.

2. Altman H, Steinberg D, Porat Y, Mor A, Fridman D, Friedman M, et al. In vitro assessment of antimicrobial peptides as potential agents against several oral bacteria. Journal of Antimicrobial Chemotherapy. 2006;58(1):198-201.

3. Yaghobee S, Khorsand A, Paknejad M. Comparison of interleukin-1 $\beta$ levels in gingival crevicular fluid and peri-implant crevicular fluid and its relationship with clinical indexes. Journal of Dentistry of Tehran University of Medical Sciences. 2013;10(1):1-9.

4. Faizuddin M, Bharathi S, Rohini N. Estimation of interleukin- $1 \beta$ levels in the gingival crevicular fluid in health and in inflammatory periodontal disease. Journal of periodontal research. 2003;38(2):111-4.

5. Bals R. Epithelial antimicrobial peptides in host defense against infection. Respiratory research. 2000;1(3):14150.

6. Lundy FT, O'Hare MM, McKibben BM, Fulton CR, Briggs JE, Linden GJ. Radioimmunoassay quantification of adrenomedullin in human gingival crevicular fluid. Archives of oral biology. 2006;51(4):334-8.

7. Allaker RP, Grosvenor PW, McAnerney DC, Sheehan BE, Srikanta BH, Pell K, et al. Mechanisms of adrenomedullin antimicrobial action. Peptides. 2006;27(4):661-6.

8. Santos VR, Ribeiro FV, Lima JA, Napimoga MH, Bastos MF, Duarte PM. Cytokine levels in sites of chronic periodontitis of poorly controlled and well-controlled type 2 diabetic subjects. Journal of clinical periodontology. 2010;37(12):1049-58.

9. Teng Y-T. Protective and destructive immunity in the periodontium: part 1-innate and humoral immunity and the periodontium. Journal of dental research. 2006;85(3):198-208.

10. Suchetha A, Garg A, Lakshmi P, Bhat D, Sapna N, Apoorva S. -Adrenomedullin, periodontitis, diabetesunraveling the equivocal relationship: A clinicobiochemical cross sectional study Contemporary clinical dentistry. 2013;4(4):454-9.

11. Dale BA, Fredericks LP. Antimicrobial peptides in the oral environment: expression and function in health and disease. Current issues in molecular biology. 2005;7(2):119-33.

12. Gupta G. Gingival crevicular fluid as a periodontal diagnostic indicator-II: inflammatory mediators, hostresponse modifiers and chair side diagnostic aids. Journal of medicine and life. 2013;6(1):7-13.

13. Barros SP, Williams R, Offenbacher S, Morelli T. Gingival crevicular fluid as a source of biomarkers for periodontitis. Periodontology 2000. 2016;70(1):53-64.

14. Okada H, Murakami S. Cytokine expression in periodontal health and disease. Critical Reviews in Oral Biology \& Medicine. 1998;9(3):248-66.

15. Gorr SU. Antimicrobial peptides of the oral cavity. Periodontology 2000. 2009;51(1):152-80.

16. Lamster IB, Ahlo JK. Analysis of gingival crevicular fluid as applied to the diagnosis of oral and systemic diseases. Annals of the New York Academy of Sciences. 2007;1098(1):216-29. 
17. Griffiths G, Wilton J, Curtis M. Contamination of human gingival crevicular fluid by plaque and saliva. Archives of oral biology. 1992;37(7):559-64.

18. Ghodpage PS, Kolte RA, Kolte AP, Gupta M. Influence of phase I periodontal therapy on levels of matrix metalloproteinase 1 and tissue inhibitor of metalloproteinase 1. The Saudi dental journal. 2014;26(4):171-5.

19. Lamster I, Ahlo J. Analysis of gingival crevicular fluid as applied to the diagnosis of oral and systemic diseases. Ann N Y Acad Sci. 2007;1098:216-29.

20. AbdulAziz S, Madhav G, Tabita B, Adinath N, Milsee M, Mohammed N. Effect of Nonsurgical Periodontal Therapy on Some Oxidative Stress Markers in Patients with Chronic Periodontitis: A Biochemical Study. World Journal of Dentistry. 2013;4:17-23.

21. Carvalho L, D'avila G, Leao A, Haffajee A, Socransky S, Feres M. Scaling and root planing, systemic metronidazole and professional plaque removal in the treatment of chronic periodontitis in a Brazilian population. Journal of clinical periodontology. 2004;31(12):1070-6.

22. Zhong Y, Slade GD, Beck JD, Offenbacher S. Gingival crevicular fluid interleukin-1 $\beta$, prostaglandin E2 and periodontal status in a community population. Journal of clinical periodontology. 2007;34(4):285-93.

23. Rosalem W, Rescala B, Teles RP, Fischer R, Gustafsson A, Figueredo C. Effect of non-surgical treatment on chronic and aggressive periodontitis: clinical, immunologic, and microbiologic findings. Journal of periodontology. 2011;82(7):979-89.

24. Engebretson SP, Grbic JT, Singer R, Lamster IB. GCF IL-1 $\beta$ profiles in periodontal disease. Journal of clinical periodontology. 2002;29(1):48-53.

25. Yousefimanesh H, Robati M, Jahangirnezhad M, Ghafourian M, Jamili R, Jafari P. Evaluation of non surgical treatment effect on salivary interleukin-1 beta (IL $1 \beta$ ) in patientswith periodontitis. E-Journal of Dentistry. 2014;4(4):656-62.

26. Türkoğlu O, Emingil G, Kütükçüler N, Atilla G. Evaluation of gingival crevicular fluid adrenomedullin and human neutrophil peptide 1-3 levels of patients with different periodontal diseases. Journal of periodontology. 2010;81(2):284-91.

27. Kapas S, Pahal K, Cruchley A, Hagi-Pavli E, Hinson J. Expression of adrenomedullin and its receptors in human salivary tissue. Journal of dental research. 2004;83(4):333-7.

28. Elsasser TH, Kahl S. Adrenomedullin has multiple roles in disease stress: development and remission of the inflammatory response. Microscopy research and technique. 2002;57(2):120-9.

29. Lim SC, Morgenthaler NG, Subramaniam T, Wu YS, Goh SK, Sum CF. The relationship between adrenomedullin, metabolic factors, and vascular function in individuals with type 2 diabetes. Diabetes Care. 2007;30(6):1513-9.

30. Ruzicska E, Toth M, Tulassay Z, Somogyi A. Adrenomedullin and diabetes mellitus. Diabetes/metabolism research and reviews. 2001;17(5):321-9.

31. Kapas S, Bansal A, Bhargava V, Maher R, Malli D, Hagi-Pavli E, et al. Adrenomedullin expression in pathogen-challenged oral epithelial cells. Peptides. 2001;22(9):1485-9.

32. Lamster IB, Oshrain RL, Gordon JM. Enzyme activity in human gingival crevicular fluid: considerations in data reporting based on analysis of individual crevicular sites. Journal of Clinical Periodontology. 1986;13(8):799804.

33. Hosokawa I, Hosokawa Y, Ozaki K, Nakae H, Matsuo T. Adrenomedullin suppresses tumour necrosis factor alpha-induced CXC chemokine ligand 10 production by human gingival fibroblasts. Clinical \& Experimental Immunology. 2008;152(3):568-75.

34. Isumi Y, Minamino N, Katafuchi T, Yoshioka M, Tsuji T, Kangawa K, et al. Adrenomedullin production in fibroblasts: its possible function as a growth regulator of Swiss 3T3 cells. Endocrinology. 1998;139(5):2552-63.

35. Sugo S, Minamino N, Shoji H, Kangawa K, Kitamura K, Eto T, et al. Interleukin-1, Tumor Necrosis Factor and Lipopolysaccharide Additively Stimulate Production of Adrenomedullin in Vascular Smooth Muscle Cells. Biochemical and Biophysical Research Communications. 1995;207(1):25-32. 